\title{
LITERATURA JUVENIL E FORMAÇÃO DO LEITOR: ANÁLISE DA OBRA $O$ RAPAZ QUE NÃO ERA DE LIVERPOOL
}

\author{
Alan de Luna Ribeiro Fernandes
}

\section{RESUMO}

A literatura juvenil tem se destacado nas últimas décadas, as narrativas publicadas tornam-se cifras cada vez maiores e entre elas surgem narrativas cuja qualidade estética se destaca no panorama nacional. Assim, assumindo a qualidade estética da produção literária voltada para o público jovem, o presente trabalho tem se propõe a investigar possibilidades de leitura e formação do leitor que procuram despertar o gosto literário em crianças e adolescentes, tanto pela atualidade dos temas das narrativas e suas relações diretas com o mundo do leitor quanto pelo diálogo que se pode estabelecer com a "outra" literatura. Será analisada a obra O rapaz que não era de Liverpool (2006), de Caio Riter, com o intuito de reafirmar sua qualidade literária, suas intertextualidades com a "outra" literatura e propor novas leituras dessa narrativa. Pretende-se com esses estudos contribuir para um conhecimento mais vertical de literatura juvenil brasileira contemporânea no sentido de valorizar esse gênero ainda marginalizado pela crítica.

A emergência das literaturas infantil e juvenil é um fenômeno razoavelmente recente na história da literatura e, embora suas raízes remontem a um passado de proximidade com a didática, hoje o mercado editorial oferece uma gama imensa de obras e escritores comprometidos com a qualidade estética nas narrativas. Além disso, há prêmios literários que legitimam essa produção, reiterando suas qualidades estéticas.

O surgimento das literaturas infantil e juvenil está atrelado à ascensão do capitalismo e de seu modelo de vida e transmissão de valores, pois é nesse contexto que a infância e, ainda mais recentemente, a adolescência adquirem espaços separados diferentes do universo adulto. Assim, com o aumento do poder da burguesia, surgiu uma nova ideologia, ainda em construção: a ideologia burguesa familista, na qual a família que, não mais à moda colonial, tem os papéis divididos: o pai tem a função de sustentar financeiramente o pequeno grupo; a mãe torna-se responsável pelo lar e provedora afetiva; e, nesse novo cenário, a criança passa a ser o centro de interesse do grupo familiar, em sentido à conservação do status quo. (ZILBERMAN, 1998)

Se por um lado a criança passa a ter maior importância no núcleo familiar, por outro faz-se necessário prepara-la para participar no mesmo sistema econômico. Portanto, da mesma maneira, a escola passa a ter igual importância nesse novo momento econômico, pois cabe à escola a preparação da criança para o mundo adulto, a habilitação para o consumo de obras impressas e a transmissão de valores como as "normas sociais em vigor e a obediência aos interesses do Estado, quais sejam, a valorização da Pátria e suas instituições" (ZILBERMAN, 1998, p. 96).

Deste modo, a literatura infantojuvenil desponta nesse cenário como extensão da escola, adquire, inicialmente, função pedagógica servindo de apoio didático ao professor. Sob esse ponto de vista, família, literatura infantojuvenil e escola têm relações estreitas com a legitimação e manutenção do novo sistema vigente, 


\section{SEMINÁRIO DE PESQUISA EM CIÊNCIAS HUMANAS - SEPECH \\ Humanidades, Estado e desafios didático-científicos \\ Londrina, 27 a 29 de julho de 2016}

principalmente no início da nova fase econômica, quando os primeiros escritos de literatura infantil, final do século XIX, servem ao propósito didático.

Da emergência dessa literatura à atualidade passaram-se décadas de proximidade com a didática, o ideal pedagógico da literatura infantojuvenil brasileira permanece, com raras exceções, como, por exemplo, Monteiro Lobato, até a década de 60 quando o aumento dos investimentos do ramo editorial nesse "subgênero" literário viabilizam a profissionalização do escritor e a criação de instituições voltadas para o "subgênero", como a Fundação Nacional do Livro Infantil e Juvenil, fundada em 1968, e programas direcionados à promoção da leitura e da discussão de literatura infantojuvenil aceleram o seu crescimento.

O contexto político-econômico da década de 60 aumenta não apenas a produção original nacional, mas também seu prestígio literário. Aliado à nova fase econômica de enfraquecimento da burguesia agrária, tradicional, em detrimento ao fortalecimento da burguesia industrial, bem como a industrialização da cultura, ocasionam um novo painel social e novas temáticas para a literatura, o que cede espaço a uma tendência contestadora e engajada. (LAJOLO; ZILBERMAN, 2002)

No discurso pedagogizante, utilitário, o universo e a linguagem infantil e juvenil eram desprivilegiados em prol de um didatismo de qualidade literária questionável que ao mesmo tempo não representava a criança e o adolescente em seus conflitos com a realidade circundante. Para Zilberman (1998, p.23), a literatura infantojuvenil

[...] atinge o estatuto de arte literária e se distancia de sua origem comprometida com a pedagogia, quando apresenta textos de valor artístico aos seus pequenos leitores. E não é porque estes ainda não atingiram o status de adultos que merecem uma produção literária menor.

Deste modo, no Brasil o texto literário infantil e juvenil e a escola estão correlacionados desde o surgimento destas formas literárias. Contudo, a validação estética dos gêneros literários infantil e juvenil apenas acontece diante do distanciamento da didática e da aproximação com os sujeitos criança e adolescente. Ainda assim, a instituição escolar mantém seu papel na formação da criança e do adolescente leitor, para Zilberman (1994, p.21), a escola e a literatura compartilham uma "natureza formativa", porém a exercem de maneiras diferentes.

Para a pesquisadora, enquanto a literatura, por meio da ficção proporciona vários pontos de contato com a vida do leitor e,

por mais exacerbada que seja a fantasia do escritor ou mais distanciadas e diferentes as circunstâncias de espaço e tempo dentro das quais a obra é concebida, o sintoma de sua sobrevivência é o fato de que ela continua a se comunicar com o destinatário atual, porque ainda fala de seu mundo, com suas dificuldades e soluções, ajudandoo, pois, a conhece-lo melhor. (1994, p.22)

A escola, por outro lado, ainda segundo a pesquisadora, "transforma e a realidade viva nas distintas disciplinas ou área de conhecimento que são apresentadas ao estudante" (1994, p.22), contudo, convertida em aluno no processo didático, a criança é 


\section{SEMINÁRIO DE PESQUISA EM CIÊNCIAS HUMANAS - SEPECH \\ Humanidades, Estado e desafios didático-científicos \\ Londrina, 27 a 29 de julho de 2016}

enclausurada no contexto escolar e inserida em um meio em não exerce poder decisório algum.

A pesquisadora Eliane A. G. R. Ferreira, na tese Construindo histórias de leitura: a leitura dialógica enquanto elemento de articulação no interior de uma "biblioteca vivida"(2008), indica que, como verificou durante o exercício da docência, o estudo da literatura que se faz nas escolas afasta o aluno do gosto literário, pois "a abordagem do texto escrito era um debruçar sobre o objeto de análise como um fim em si mesmo e o aluno não era considerado em suas percepções, sentimentos e criatividade" (2008, p.20).

Desta maneira, a literatura estudada no contexto escolar não tem em vista o objeto artístico e o prazer pela leitura de qualidade estética, mas pressupõe uma sujeição do objeto artístico à pedagogia, por isso, Ferreira aponta que quando perguntados sobre o conceito de leitura os alunos respondiam que a leitura servia para instrução, aumento de vocabulário, escrever melhor, fazer exercício, preencher lacunas, testar a memória e passar moral, para ela, faltava aos alunos contato com língua provocadora, crítica, original e prazerosa proporcionado pelo texto literário $(2008$, p.38).

Pode-se dizer, portanto, que leitura do texto literário enquanto ferramenta da didática desfavorece o desenvolvimento do gosto pela literatura de qualidade nas crianças e adolescentes, uma vez que que não lhes é permitida a introjeção no texto literário porque este é utilizado nas suas instâncias mais superficiais. Entretanto, a posição contrária pode ser tomada pelo professor em sala de aula, o que, segundo Zilberman (1994), acarreta uma mudança de rumos nos textos escolhidos pelo professor e na adequação deles ao público leitor (p.22).

A pesquisadora postula que a primeira mudança está no critério de escolha dos textos pelo professor, para ela a escolha deve pautar-se pela qualidade estética da obra literária, pois, para ela, os critérios que separam o bom do mau texto para os jovens leitores não são diferentes daqueles que separam qualquer outra forma de criação literária (1994, p. 23). Sendo assim,

Seu aspecto inovador merece destaque, na medida em que é o ponto de partida para a revelação de uma visão original da realidade, atraindo seu beneficiário para o mundo com o qual convivia diariamente, mas que desconhecia. Neste sentido, o índice de renovação de uma obra ficcional está na razão direta de sua oferta de conhecimento de uma circunstância da qual, de algum modo, o leitor faz parte. (1994, p.23)

O destaque para o critério literário enquanto direção para a escolha das obras guia o professor para um novo tratamento do texto estético. Contrário ao ensino tradicional no qual o professor, detentor do saber, apresentava uma leitura singular do texto, leva o professor a realizar a leitura diante das multiplicidades semânticas da obra literária, enfatizando-as e levando à formação do aluno enquanto leitor crítico. Deste modo, diante da multiplicidade de visões que a leitura da literatura oferece o aluno reflete sobre sua participação na realidade circundante, propiciando a emancipação pessoal (1994, p.25)

Embora Regina Zilberman tenha escrito seu livro A literatura infantil na escola pensando no público infantil, a proposta de leitura apresentada pela pesquisadora 


\section{SEMINÁRIO DE PESQUISA EM CIÊNCIAS HUMANAS - SEPECH \\ Humanidades, Estado e desafios didático-científicos \\ Londrina, 27 a 29 de julho de 2016}

também tem validade para a leitura das narrativas juvenis em sala de aula, uma vez que realiza o encontro entre aluno e obra de arte de maneira crítica, expondo a face formativa da estética literária que, distante da didática, proporciona uma introjeção do leitor no objeto artístico e sua reflexão sobre a sua realidade.

Contudo, outra questão se faz presente, onde o professor pode encontrar narrativas juvenis de qualidade estética para trabalhar em sala de aula? Se por um lado, por sua raiz historicamente próxima à didática ou por certa proximidade ao universo mercadológico, as literaturas infantil e juvenil enfrentam certo "desprestígio" acadêmico sendo rotuladas por "subgênero" ou "paraliteratura" pela crítica, termo por vezes utilizado com uma conotação negativa referindo-se a uma produção literária "menor". Além disso, há pouca produção acadêmica relacionada aos gêneros infantil e juvenil, segundo Ceccantini (2000), os estudos nessa área ainda são pouco para compreender o fenômeno e propor métodos mais apropriados para análise. O problema da falta de pesquisas nesse campo mostra uma lacuna aberta nos estudos literários, a falta de estudos que legitimem as produções literárias nos gêneros infantil e juvenil.

Por outro lado, há outras instâncias que legitimam tal produção estética, como os prêmios Jabuti, concedido pela Câmara Brasileira do Livro, Prêmio FNLIJ, concedido pela Fundação Nacional do Livro Infantil e Juvenil, Prêmio Orígenes Lessa, concedido pela Associação Paulista de Críticos de Arte e Prêmio Barco a vapor, concedido pela Fundação SM, que contam com a crítica especializada para compor o júri e realizar a premiação.

Nesse sentido, a produção literária de Caio Riter adquire legitimidade do seu valor estético nas premiações recebidas até o momento. $\mathrm{O}$ autor é graduado em Comunicação Social e em Letras com Mestrado e Doutorado em Literatura Brasileira, possui vasta produção literária em literatura infantil e juvenil, estreou em 1994 com a publicação do livro infantil Um palito diferente pela editora Interpreta Vida em Porto Alegre, sua produção voltada para o público jovem iniciou-se em 2001 com a publicação de Chico pela editora WS Editor. Segundo a pesquisadora Alice Áurea Penteado Martha, o reconhecimento à obra de Caio Riter inicia-se em 1997

\footnotetext{
com a premiação ao poema "Pão", no Concurso Literário Poemas no ônibus, realizado em Porto Alegre; desde então, suas produções têm recebido menções honrosas, tem sido selecionadas, pelo MEC/PNBE para compor o acervo das bibliotecas das escolas brasileiras e têm sido incluídas em Catálogos de Feiras Internacionais de Livros, como o Catálogo de Bolonha. (MARTHA, 2012, p. 170)
}

Suas narrativas abordam diversas temáticas pertinentes à vida urbana do jovem contemporâneo; neles os protagonistas problematizam seu lugar, identidade e participação na família e na sociedade, segundo Martha, as principais temáticas são as conquistas e perdas das personagens jovens nos ambientes em que transitam (2012, p.170). Deste modo, em várias narrativas o drama situa-se em relação à família, por vezes o jovem problemático em relação aos adultos negligentes, ou à ausência ou abandono dos pais.

A obra O rapaz que não era de Liverpool, de Caio Riter, ilustrada por Graça Lima, foi publicada em 2006 pela editora Edições SM, a obra recebeu o Prêmio Barco a vapor em (2005), Prêmio Orígenes Lessa (2007), selo Altamente recomendável 


\section{SEMINÁRIO DE PESQUISA EM CIÊNCIAS HUMANAS - SEPECH \\ Humanidades, Estado e desafios didático-científicos \\ Londrina, 27 a 29 de julho de 2016}

concedido pela Fundação Nacional do Livro Infantil e Juvenil (2007), Prêmio Açorianos de Literatura, concedido pela Secretaria de Cultura de Porto Alegre e finalista ao Prêmio de livro do ano pela Associação Gaúcha de Escritores - AGES (2007).

A narrativa é repleta de referências à literatura, ao poeta mineiro Affonso Romano de Sant'Anna, aos romances Robinson Crusoé, de Daniel Defoe, e Alice no país das maravilhas, de Lewis Carol, à peça de teatro Sonhos de uma noite de verão, de William Shakespeare, e às músicas dos Beatles, sendo que, além das referências feitas pelo protagonista apaixonado pela banda, cada capítulo leva no título um trecho de música do quarteto de Liverpool. A obra é dividida em 6 capítulos e 17 subcapítulos intitulados por "cenas" da vida do protagonista.

Em O rapaz que não era de Liverpool o protagonista, Marcelo, jovem de quinze anos, amante das músicas do Beatles, descobre durante uma aula de biologia que é adotado. A partir da descoberta da adoção inicia a narrativa contada pelo próprio protagonista em agitado estado emocional que, em meio ao drama, se questiona sobre as mentiras e seu lugar na família enquanto rememora cenas de sua vida.

O jovem narrador problematiza em sua solidão sobre seu lugar na família, Martha (2012), ressalta a importância do modo de narrar na obra, pois, segundo ela, revela, em seu drama interior, a impossibilidade de evasão, a dificuldade de distanciamento e observação de sentimentos alheios (2012, p.171). Para a pesquisadora:

O narrador, limitado à própria perspectiva, nesse momento, inteiramente dedicado ao resgate de sua identidade, não busca reconhecer sentimentos e emoções das demais personagens, recurso bastante adequado, uma vez que o percurso do jovem é marcado por crises de identidade, por reflexões existenciais. Podemos dizer que o estatuto de semelhante narrador é funcional, pertinente ao assunto narrado (...) Marcelo encontra-se em fase limítrofe, por atravessar momento naturalmente difícil da adolescência e porque registra na pele, ou melhor, na cor dos olhos, a eficácia da lei de Mendel, o que explica seu modo de narrar, a quase impossibilidade de sair do invólucro e observar sentimentos alheios, especialmente, as emoções experimentadas pelos pais, a seu ver, responsáveis por todo seu drama interior. (2010, p. 131-132)

A obra também é objeto de estudo do pesquisador Celso Sisto, que, a partir do autocentramento do narrador, investiga elementos (espelho, labirinto, o fio de Ariadne e o pão da palavra) na obra que, segundo ele, poderiam atrair o olhar do jovem leitor pela a necessidade de reconhecer-se no outro e o desejo ardente de fazer parte de um grupo; o dever de atravessar os conflitos e sair vencedor; a possibilidade de encontrar neste trajeto a ajuda de alguém mais bem preparado; e a obrigação quase moral de relatar essa aventura de viver (2011, p. 245).

Para este pesquisador, os quatro elementos supracitados podem ser encontrados na narrativa de $O$ rapaz que não era de Liverpool. O primeiro deles dá-se à medida que se questiona sobre sua identidade e sua verdadeira família; no segundo o narrador perdido em sua busca pela identidade envereda-se em seu interior num constante ir e vir de suas memórias para no terceiro elemento receber a ajuda de outros personagens, como a namorada, DJ, que o ajudam a superar o problema; por fim, o quarto elemento é 


\section{SEMINÁRIO DE PESQUISA EM CIÊNCIAS HUMANAS - SEPECH \\ Humanidades, Estado e desafios didático-científicos \\ Londrina, 27 a 29 de julho de 2016}

a própria escrita da narrativa, um elemento metalinguístico, em que o protagonista se circunscreve naquela realidade.

O narrador homodiegético de $O$ rapaz que não era de Liverpool é também uma personagem problemática em busca de sua identidade perdida pelo descobrimento da adoção. Uma série de acontecimentos que se descobre anteriores ao descobrimento da adoção atuam o estado psicológico de protagonista, dentre eles, e de maior importância, a separação dos pais, que revela uma personagem jovem diante de um contexto familiar divido e desarmonizado. Assim a narrativa que se inicia com a dramática afirmação da mãe de Marcelo "Não, Marcelo, você não nasceu de mim!" (2015, p. 9) se envereda pela introspecção de uma personagem diante do turbilhão de sentimentos de frustração e de não pertencimento àquele lar.

A busca de Marcelo pela identidade esbarra no retorno ao equilíbrio e à harmonia perdida, ao voltar-se para seu interior conflituoso, com suas idas e vindas nas lembranças e a revolta contra a decisão dos pais de terem escondido sua "verdadeira identidade" por tanto tempo, representa uma passagem de estado pelo enfrentamento de sua condição, não se acomoda passivamente, mas supera a solidão.

Contudo, a superação do autoexílio de Marcelo não acontece apenas na superação de sua solidão e reequilíbrio com a realidade familiar, mas as atravessa e culmina no exercício da escrita: "E antes de sair para o encontro com minha turma, pego meu caderno e escrevo a cena 17. Preciso encerrar este pedaço da minha história, para que outra possa surgir. " (2015, p.100)

Portanto, a busca pela identidade na narrativa de introspecção psicológica feita pelo protagonista Marcelo bem como a superação de sua condição de solidão mostra um protagonista em formação, conflitante com sua realidade. Na tese Uma estética da formação: vinte anos de literatura juvenil premiada (2000), Ceccantini verifica a presença de uma "estética de formação", termo utilizado pelo pesquisador para conciliar a condição de arte das narrativas juvenis à temática de formação presente central e perifericamente, formação do leitor e à formação da literatura de um ponto de vista mais amplo afinado com as considerações sobre a literatura e formação do homem de Antônio Candido.

A noção de uma "estética de formação" postulada por Ceccantini é utilizada por Larissa W. F. Cruvinel, na tese Narrativas juvenis brasileiras: em busca da especificidade do gênero, dando continuidade à discussão do "específico juvenil". A partir da recorrência da temática da formação nas narrativas estudadas a pesquisadora apresenta a hipótese de uma preocupação em configurar-se um processo de preparação para a vida nas narrativas juvenis. A partir do corpus analisado a pesquisadora conclui que as narrativas

apresentam a tendência de formar uma conduta ética nos protagonistas, de modo que temas como o bullying, a anorexia nervosa, os padrões de beleza, o uso de drogas, a questão da responsabilidade no trânsito, entre outros, buscam levar o leitor a refletir a respeito de um comportamento para as condutas humanas. (2015, p.168) 


\section{SEMINÁRIO DE PESQUISA EM CIÊNCIAS HUMANAS - SEPECH \\ Humanidades, Estado e desafios didático-científicos \\ Londrina, 27 a 29 de julho de 2016}

Em confluência com estes pesquisadores, Alice Áurea Penteado Martha, em artigo, ao analisar diversas narrativas juvenis, dentre elas $O$ rapaz que não era de Liverpool, conclui que

[...]relatam o desabrochar sentimental, a aprendizagem humana dos protagonistas, jovens que buscam o conhecimento de si mesmos e dos outros e participam gradativamente na aventura da existência. Por essa razão, entendemos que mesmo os minicontos de Brasiliense podem ser considerados narrativas de formação, subgênero muito próximo do Bildungsroman (romance de formação). (2008, p.10)

Assim, narrativa juvenil $O$ rapaz que não era de Liverpool, insere-se nesse grupo seleto de narrativas de qualidade estética, uma vez que além de apresentar certa ruptura com os modelos formais, seja no narrador homodiegético e na quebra da ordem direta na cronologia, seja na nomeação dos capítulos e diálogos com a música contemporânea; apresenta traços do romance de formação de maneira a buscar a emancipação do protagonista.

Além disso, a leitura desta narrativa e seus pontos de contato com o jovem leitor proporciona, por meio da estética, sua formação, em sentido lato. Como expõe Cruvinel (2015), o contato com o livro enquanto obra de arte, oferece uma aprendizagem ética distante da didática na qual o "subgênero" tem suas raízes históricas atrelada, ou, nas palavras de Martha (2008, p. 16)

Nessas narrativas, o que desperta a atenção dos leitores, na ênfase no processo de construção das personagens, é o fato de que a infância e a adolescência não são vistas como preparação para a maturidade, mas enfocadas como etapas decisivas no processo de vida, plenas de significado e valor, portanto. Em outras palavras, as personagens não são construídas como ainda-não-adultos ou já-não-mais-crianças, são portadoras de uma identidade própria e completa. É verdade também que se envolvem em situações que as obrigam a refletir e reformular conceitos que possuem a respeito de $\mathrm{s}$ mesmas e do mundo.

Por fim, realizar a leitura de obras juvenis que, como qualquer outra forma literária, de qualidade estética é pôr o jovem em contato a obra de arte e seu caráter transformador. Se por um lado a leitura utilitária do texto literário realizada em sala de aula torna o contato com a literatura enfadonho, por outro a leitura dialógica da literatura de qualidade apresenta uma multiplicidade de sentidos que, se não tem valor útil enquanto veiculação de regras gramaticais, vocabulário e memória, proporciona aprendizagens éticas ao leitor nos múltiplos contatos com a própria vida que a literatura realiza e, nesse sentido, a leitura transforma-se em um ato de formação do ser, e não apenas d aluno. 


\section{SEMINÁRIO DE PESQUISA EM CIÊNCIAS HUMANAS - SEPECH \\ Humanidades, Estado e desafios didático-científicos \\ Londrina, 27 a 29 de julho de 2016}

\section{REFERÊNCIAS}

AGUIAR, Vera Teixeira de. Literatura juvenil existe? Questões de identidade. In: Congresso Internacional de Americanistas.53., 2009, Cidade do México. Anais... Cidade do México: Universidade Ibero-americana, 2009.

AGUIAR, Vera Teixeira de; CECCANTINI, João Luís; MARTHA, Alice Áurea Penteado (orgs). Narrativas juvenis: geração 2000. São Paulo, SP: Cultura Acadêmica, 2012.

CANDIDO, Antonio. A literatura e a formação do homem. Ciência e Cultura, v. 24, n. 9, p. 803-809, set. 1972.

CECCANTINI, João Luís. Uma estética de formação: vinte anos de literatura juvenil brasileira premiada (1978 - 1997). 2000. Tese (Doutorado) - Faculdade de Ciências e Letras de Assis, Universidade Estadual Paulista, Assis. 2000

CECCANTINI, João Luís; PEREIRA, Rony Farto. Conflito de gerações, conflito de culturas: um estudo de personagens em narrativas juvenis brasileiras e galegas. Letras de Hoje. Porto Alegre, v. 45, n.3, p. 80-85, jul./set. 2010.

CRUVINEL, por Larissa W. F. Cruvinel. Narrativas juvenis brasileiras: em busca da especificidade do gênero. 2009. Tese (Doutorado) - Universidade Federal de Goiás, Faculdade de Letras.

FERREIRA, Eliane Aparecida Galvão Ribeiro. Construindo histórias de leitura: a leitura dialógica enquanto elemento de articulação no interior de uma "biblioteca vivida". 2008. Tese (doutorado) - - Faculdade de Ciências e Letras de Assis, Universidade Estadual Paulista, Assis. 2008.

LAJOLO, Marisa. ZILBERMAN, Regina. Literatura. Literatura infantil brasileira: história \& histórias. 6. ed. São Paulo: Ática, 2002.

LUKÁCS, Georg. A teoria do romance. São Paulo: Editora 34, 2000.

MARTHA, Alice Áurea Penteado. A literatura infantil e juvenil: produção brasileira contemporânea. Letras de hoje. Porto Alegre, v. 43. No 02. Abr./Jun. 2008. p.09-16.

MARTHA, Alice Áurea Penteado. Diários de Jovens: confissões e ficção. In: AGUIAR, Vera Teixeira de; CECCANTINI, João Luís; MARTHA, Alice Áurea Penteado (orgs). Narrativas juvenis: geração 2000. São Paulo, SP: Cultura Acadêmica, 2012, p.161182.

MARTHA, Alice Áurea Penteado. No olho do furacão: situações-limite na narrativa juvenil. In: AGUIAR, Vera Teixeira de; CECCANTINI, João Luís; MARTHA, Alice Áurea Penteado (orgs). Heróis contra a parede: estudos de literatura infantil e juvenil. São Paulo, SP: Cultura Acadêmica, 2010, p.121-142. 
PERROTTI, Edmir. O texto sedutor na literatura infantil. São Paulo: Icone, 1986.

RITER, Caio. O rapaz que não era de Liverpool. 2.ed. São Paulo: SM Editora, 2015.

SISTO, Celso. O espelho, o labirinto, o fio de Ariadne e o pão da palavra: elementos da literatura juvenil. Travessias. Vol. 5, No 1. 2011, p. 243-257. Disponível em < http://erevista.unioeste.br/index.php/travessias/article/view/5279/3938> Acesso em: 30 mai. 2016.

SOUZA, Raquel Cristina de Souza e. A ficção juvenil brasileira em busca de identidade: a formação do campo e do leitor. 2015. Tese (doutorado) - Universidade Federal do Rio de Janeiro, Faculdade de Letras, Programa de Pós Graduação em Letras Vernáculas, 2015.

ZILBERMAN, Regina. A literatura infantil na escola. 10. ed. São Paulo: Global, 1998.

ZILBERMAN. Regina. Literatura Infantil: livro, leitura e leitor. Porto Alegre: Mercado Aberto, 1982. 